\title{
APTIDÃO CLIMÁTICA DA CULTURA DA BANANA NO ESTADO DO PIAUÍ - BRASIL
}

\author{
Manoel Vieira de França, Raimundo Mainar de Medeiros, Romildo Morant de Holanda
}

Universidade Federal Rural de Pernambuco - UFRPE, Departamento de Tecnologia Rural, Recife, PE. E-mail: manoelvieiraufrpe@gmail.com

\section{RESUMO}

O presente estudo expõe os elementos meteorológicos, fatores climáticos, balanço hídrico climatológico (BHC) desenvolvido por Thornthwaite e Mather, classificação climática pelos métodos de Thornthwaite e Köppen para estado do Piauí seguido de sua classificação para o cultivo de banana. Utilizou-se os dados de precipitações climatológicas médias mensais e anuais adquiridos do banco de dados coletado pela Superintendência de Desenvolvimento do Nordeste - SUDENE (1990) e da Empresa de Assistência Técnica e Extensão Rural do Estado do Piauí - EMATER-PI, os valores mensais e anuais de temperatura do ar foram estimados pelo método das retas de regressões lineares múltiplas utilizando-se do software Estima-T e do Instituto Nacional de Meteorologia (INMET). O vento pode ser um dos fatores limitantes para a exploração comercial da bananicultura, se as cultivares forem de porte alto e plantado em solos arenosos. Em locais com elevada insolação, o período para que o cacho atinja o ponto de corte oscila entre 80 e 90 dias. Sob pouca insolação, este período de corte variar entre 85 e 112 dias após a sua emissão. A bananeira que deve ser cultivada em locais que variam de 0 a 1.000 metros acima do nível do mar demostram altimetria dentro das citações de diversos autores. As oscilações na altitude alteram a duração do ciclo da bananeira, evidenciando-se que há um aumento de 30 a 45 dias no ciclo de produção desta cultura para cada $100 \mathrm{~m}$ de acréscimo na altitude.

Palavras-chave: elementos climáticos; implantação e aptidão agrícola; deficiência e excedente hídrico.

\section{FITNESS CLIMATE OF CULTURE BANANA IN STATE PIAUÍ - BRAZIL}

\begin{abstract}
This study exposes the weather elements, climatic factors, climatic water balance (BHC) developed by Thornthwaite and Mather, climatic classification by the methods of Thornthwaite and Köppen to the state of Piauí followed by its rating for banana cultivation. It used data from climatological precipitation monthly and annual averages acquired from the database collected by the Superintendence of Northeast Development - SUDENE (1990) and Business Technical Assistance and Rural Piauí State Extension - EMATER$\mathrm{PI}$, the monthly figures and air temperature year were estimated by the method of lines of multiple linear regressions using the estimated $T$ and the National Institute of Meteorology software (INMET). The wind can be a limiting factor for the commercial exploitation of the banana crop; the cultivars are high-sized and planted in sandy soils. In places with high insolation, the period for the bunch reaches the cutoff point is between 80 and 90 days. Under little sunshine, this cutting period vary between 85 and 112 days after issue. The banana should be grown in places that range from 0 to 1000 meters above sea level altimetry demonstrate within the quotes from various authors. Fluctuations in the altitude change the length of the banana cycle, indicating that there was an increase of 30 to 45 days in the cycle of production of culture for every $100 \mathrm{~m}$ increase in altitude.
\end{abstract}

Key words: weather elements; deployment and agricultural potential; deficit and surplus.

\section{INTRODUÇÃO}

A bananeira é uma planta tipicamente tropical, exigente em temperaturas elevadas, precipitação bem distribuída e disponibilidade de umidade no solo. A temperatura ótima para o desenvolvimento da cultura oscila em torno de $28^{\circ} \mathrm{C}$, enquanto temperaturas de $15{ }^{\circ} \mathrm{C}$ e $35,0^{\circ} \mathrm{C}$ são os limites extremos para exploração da 
cultura. Dessa forma, se uma região apresenta valores de temperatura dentro desses limites e adequado suprimento de água e nutrientes, é possível o cultivo da bananeira nessa área. Medeiros et al. (2013).

A banana (Musa sapientum) é uma das frutas tropicais mais exploradas mundialmente, devido ao seu custo relativamente baixo e ao alto valor nutritivo é parte integrante na alimentação, principalmente, das populações de baixa renda.

Das diversas fruteiras tropicais irrigadas, a bananeira é uma das mais sensíveis ao estresse hídrico, isto em função do seu elevado índice de área foliar, o que resulta em alta transpiração; o sistema radicular é muito superficial, razão pela qual a bananeira é uma espécie que apresenta considerável resposta fisiológica à escassez de água. Vosselen et al. (2005). Para definir a aptidão da região para o cultivo da bananeira, o produtor deve ter conhecimento das características climatológicas e as suas variações sazonais, uma vez que a cultura não tolera encharcamento, fortes ventos e temperaturas médias do ar abaixo de $15 \circ \mathrm{C}$. Ventura e Gomes (2005).

O conhecimento das variáveis agroclimáticas de uma região é de fundamental importância para todas as atividades humanas desenvolvidas, Medeiros et al. (2013).

A água é essencial para o desenvolvimento das culturas, a sua falta ou excesso pode influenciar na produção agrícola de determinada localidade ou de uma região. De acordo com Medeiros et al., (2013) a técnica do balanço hídrico fornece o saldo de água disponível no solo para o vegetal, ou seja, contabiliza a entrada (precipitação e ou irrigação) e a saída (evapotranspiração potencial), considerando determinada capacidade de armazenamento de água pelo solo.

Matos et al. (2014) afirmam que o uso do balanço hídrico para uma região é de suma importância, pois o mesmo considera o solo, sua textura física, profundidade efetiva do sistema radicular das plantas e o movimento de água no solo durante todo o ano.

A evapotranspiração (ETP) é o parâmetro mais importante para se determinar às necessidades hídricas da planta, pois as mesmas dependem fundamentalmente das condições microclimáticas, tais como precipitação, velocidade do vento, temperatura, umidade relativa e radiação solar; das características das plantas, entre elas, cultivar, estágio vegetativo, índice de área foliar, extensão e profundidade das raízes e atividade metabólica da planta; e ainda da água disponível no solo. FERREIRA (1988).

O zoneamento agroclimatológico constituise, numa ferramenta importante no processo de tomada de decisão, permitindo, a partir das análises das variabilidades climáticas locais e de sua espacialização, a delimitação de regiões com diferentes aptidões climáticas ao cultivo. A definição de épocas de semeaduras ajustadas aos estudos probabilísticos da distribuição temporal das chuvas, bem como a recomendação de cultivares com maiores potenciais produtivos, maior resistência ao déficit hídrico e com ciclos mais precoces podem diminuir os efeitos causados pela má distribuição das chuvas e pelo uso de tecnologias não adequadas, Silva et al., (2013).

O conhecimento da cultura que mais se adéquam às condições climáticas para o estado do Piauí proporcionará o seu desenvolvimento agrícola, tornando rentável e socioeconomicamente viável, deste modo tem-se como objetivo determinar a aptidão climática para a cultura da banana; Classificando a aptidão da cultura adequada ao plantio na região e sua classificação climática.

\section{MATERIAL E MÉTODOS}

Utilizaram-se séries mensais e anuais de precipitação pluvial com oscilações entre 30 a 100 anos de dados. Essas séries foram selecionadas com base no critério de analisar apenas aquelas sem falhas e contínuas, bem como distribuídas homogeneamente na área de estudo, para as séries que continha falhas utilizou-se o método de preenchimento. Os preenchimentos de falhas foram realizados pelos métodos da média ponderada pelo o inverso da distância ao quadrado desenvolvido em planilhas eletrônicas por Medeiros (2016). Os postos pluviométricos utilizados foram da Superintendência de Desenvolvimento do Nordeste - SUDENE (1990) e da Empresa de Assistência Técnica e Extensão Rural do Estado do Piauí - EMATER-PI abrangendo 221 postos pluviométricos com registros completos.

Foram caracterizados três cenários pluviométricos distintos designados por "cenário seco", "cenário regular" e "cenário chuvoso", usando-se a função de distribuição de probabilidade gama incompleta, conforme metodologia proposta por Varejão-Silva (2005): 
i) cenário seco - constituído por anos nos quais o total de precipitação acumulada no trimestre mais chuvoso é menor ou igual ao valor correspondente à probabilidade de $25 \%$;

ii) cenário chuvoso - constituído por anos nos quais o total de precipitação acumulada no trimestre mais chuvoso é maior ou igual ao valor correspondente à probabilidade de $75 \% \mathrm{e}$

iii) cenário regular - constituído por aqueles anos não classificados nas duas categorias anteriores. Os balanços hídricos, também, foram calculados segundo a metodologia clássica, usando-se toda a série de dados de chuva disponível, designado por "cenário médio".

No cálculo dos índices de aridez, umidade e hídrico, utilizaram-se das equações descritas abaixo. Tais índices são essenciais para a caracterização climática da região segundo o método de Thornthwaite (1948), e no estudo de adaptação de culturas à região - Zoneamento Agrícola.

Onde:

$$
\begin{gathered}
I a=100 \frac{\sum D E F}{\sum E T P} \\
I u=100 \frac{\sum E X C}{\sum E T P}
\end{gathered}
$$$$
\text { 1. } I h=I u-0,6 \cdot I a
$$

Ih= índice hídrico;

la= índice de aridez;

lu= índice de umidade;

$E X C=$ excedente hídrico oriundo do $\mathrm{BHC}(\mathrm{mm})$;

$\mathrm{DEF}=$ deficiência hídrica oriunda do $\mathrm{BHC}(\mathrm{mm})$;

$\mathrm{ETP}=$ evapotranspiração de referência ou potencial $(\mathrm{mm})$.

Os índices de umidade foram geoespacializados o que permitiu a geração da tabela de classificação climática nos cenários pluviométricos analisados. Quando a área de um determinado município apresentava dois ou mais tipos climáticos, assumiu-se que prevaleciam o tipo climático mais crítico, com área de abrangência maior ou igual a $20 \%$ da área do município em questão, Andrade (2005). Ou seja, se em determinado município ocorressem os tipos climáticos $E$ e $D$, com áreas de abrangência de $25 \%$, para o tipo climático E e $75 \%$, para o tipo climático $D$, assumiu-se que prevalecia, no referido município, o tipo climático $\mathrm{E}$. A utilização desse critério permitiu tornar a classificação climática mais homogênea.

A classificação e a aptidão climática foram obtidas de acordo com a metodologia proposta por Thornthwaite (1948) utilizando-se os valores dos índices de aridez (la), umidade (lu), hídrico (Ih) e (Cv) em conformidade com a concentração da evapotranspiração potencial na estação quente, definida pelos três meses consecutivos de temperatura mais elevada do ano.

O método adotado para obtenção do balanço hídrico climático foi o proposto por Thornthwaite e Mather (1948, 1955), com elaboração de planilhas eletrônicas realizadas por Medeiros (2014) que contabiliza a água do solo, em que a precipitação representa ganho e a evapotranspiração perda de umidade do solo, podendo-se estimar os valores correspondentes ao Excedente Hídrico (EXC) e Deficiência Hídrica (DEF). Com base nesta metodologia foi estimada a capacidade de armazenamento de água disponível no solo (CAD) de $100 \mathrm{~mm}$. A Evapotranspiração Potencial $\left(E T_{p}\right)$ foi obtida conforme a Equação abaixo.

$$
E T p=F c \cdot 16 \cdot\left(10 \frac{T}{I}\right)^{a}
$$

Onde:

$E T P=$ Evapotranspiração potencial anual em $\mathrm{mm} \cdot \mathrm{mês}^{-1}$;

$\mathrm{Fc}=$ Fator de correção, conforme a Tabela 1;

$\mathrm{T}=$ Temperatura média mensal em ${ }^{\circ} \mathrm{C}$;

I=Índice anual de calor, correspondente a soma dos doze índices mensais; $\mathrm{e}$

$a=$ Função cúbica do índice anual de calor dada por: $\quad 6,\left.75 * 10^{-7} *\right|^{3}-7,71 * 10^{-5} 5^{*}|2+0,01791 *|+0,492$ em mm.mês ${ }^{-1}$.Tabela 1. Fator de Correção (Fc) conforme a metodologia de Thornthwaite (1948) em função dos meses do ano.

Tabela1. Fator de Correção (Fc) conforme a metodologia de Thornthwaite (1948) em função dos meses do ano.

\begin{tabular}{llllllllllll}
\hline \multicolumn{11}{c}{ Fator de Correção } \\
\hline Jan & Fev & Mar & Abr & Mai & Jun & Jul & Ago & Set & Out & Nov & Dez \\
1,80 & 0,97 & 1,05 & 0,99 & 1,01 & 0,96 & 1,00 & 1,01 & 1,00 & 1,06 & 1,05 & 1,10 \\
\hline
\end{tabular}

Fonte: UNESCO (1982). 
A concentração da evapotranspiração potencial na estação quente foi dada pela Equação seguinte a qual representa a percentagem da evapotranspiração anual que ocorre nos meses j, k, l, de temperatura mais elevada do ano (trimestre mais quente).

$$
C v=100 \cdot\left(E T P_{j}+E T P_{k}+E T P_{l}\right) /(E T P)
$$

Em que:

$\mathrm{C} v$ - concentração da evapotranspiração; $\mathrm{ETP}_{\mathrm{j}}$ - evapotranspiração potencial no mês j; $\mathrm{ETP}_{\mathrm{k}}$ - evapotranspiração potencial no mês k; $E T P_{1}$ - evapotranspiração potencial no mês L; ETP - evapotranspiração potencial anual.

Realizou-se a elaboração do evapopluviograma, o qual se refere a um climograma adaptado ao BHC, para fins de estudo das condições climáticas mais adequadas às culturas, através do sistema de coordenadas ortogonais. Como nesse caso a evapotranspiração potencial é plotada em função da precipitação, assim obtém-se o evapopluviograma.

O diagrama apresenta-se dividido em seis setores hídricos, nos quais os valores da precipitação correspondem a diferentes múltiplos e submúltiplos da evapotranspiração potencial, e em outras quatro faixas térmicas com valores correspondentes às limitações e exigências térmicas da cultura.

Utilizando-se dos pontos do evapopluviograma determinaram-se os índices de vegetação (Iv), de repouso por seca (Irs) de repouso por frio (Irf) e hídrico (Ih). Por fim, os valores dos índices climáticos foram aplicados na Tabela 2 para determinação da aptidão climática da região, classificando as culturas em aptidão plena, moderada, restrita e inaptidão.

A maior parte do sistema radicular da bananeira concentra-se nos primeiros $40 \mathrm{~cm}$ de profundidade do solo. A prática da subsolagem deve ser realizada sempre que for feito o cultivo da bananeira pela primeira vez e por ocasião da reforma do plantio velho. A bananeira exige solos bem A cultura da banana tem faixas de temperaturas que contribuem para seu desenvolvimento conforme descrito abaixo:

a) Temperatura média anual $(\mathrm{Ta})=15{ }^{\circ} \mathrm{C}$ indica o limite inferior da faixa térmica apta à produção da banana. Abaixo desse limite a cultura sofre deficiência térmica, que provoca uma queda na produção, tornando-se a área restrita a inapta, para a cultura comercial.

b) Temperatura média anual (Ta) entre $15^{\circ} \mathrm{C}$ e $35^{\circ} \mathrm{C}$ indica a faixa térmica favorável à cultura da banana.

c) Temperatura média anual (Ta) maior que $35^{\circ} \mathrm{C}$ indica o limite superior da faixa térmica favorável à cultura da banana.

As temperaturas médias foram utilizadas através do software Estima-T (Cavalcanti e Silva 1994); Cavalcanti et al. 2006) e do Instituto Nacional de Meteorologia (INMET, 2017).

Na Tabela 2 tem-se a Síntese da aptidão e exigências climáticas da cultura da bananeira de acordo com Ometto (1981), aplicada a quatro tipos de aptidão: Plena; Moderada; Restrita e Inapta, para tanto se levou em consideração a flutuabilidade da deficiência hídrica municipal e realizou-se a classificação como mostrado na Tabela 3.

Tabela 2. Síntese da aptidão e exigências climáticas da cultura de acordo com Ometto (1981).

\begin{tabular}{|c|c|c|c|}
\hline Cultura & Aptidão & Índice Climático & Deficiência/Excesso \\
\hline \multirow{3}{*}{ Banana } & Plena & $\rightarrow \mathrm{DEF}<200 \mathrm{~mm}$ & $\begin{array}{l}\Rightarrow \text { Boas condições hídricas para o desenvolvimento da } \\
\text { cultura. }\end{array}$ \\
\hline & Moderada & $\rightarrow 200<\mathrm{DEF}<350 \mathrm{~mm}$ & $\begin{array}{l}\Rightarrow \text { Insuficiência hídrica estacional, prolongando o ciclo da } \\
\text { cultura. }\end{array}$ \\
\hline & Restrita & $\rightarrow 350<\mathrm{DEF}<700 \mathrm{~mm}$ & $\begin{array}{l}\Rightarrow \text { Deficiência hídrica acentuada, sendo possível o cultivo } \\
\text { apenas em várzeas e locais mais úmidos. } \\
\Rightarrow \text { Deficiência hídrica muito severa. O cultivo somente } \\
\text { possível através de irrigação. }\end{array}$ \\
\hline
\end{tabular}

Fonte: Dados da Pesquisa

\section{RESULTADOS E DISCUSSÃO}

A Tabela 3 apresenta a deficiencia hídrica e da classificação de aptidão para o cultivo da banana no estado do Piauí. Observa-se que ocorrem dois tipo de classificação: algumas áreas isoladas apresentam aptidão, porém são restritas ao cultivo, por falta de água para a irrigação nos meses de maiores deficiências hídrica e a classifcação Inapta por causa do tipo de solo. Apesar de algumas áreas restritas tem-se plantio 
de baneiras com grandes sucesso, pois estes tem

irrigação e uma excelente produtividade.

favorecimentos de solo, água abundante para a

Tabela 3. Municípios, deficiência hídrica e aptidões climáticas para a cultura da banana no estado do Piauí. Legenda: def. hídrica = deficiência hídrica; Classificação = Classificação de aptidão climática.

\begin{tabular}{|c|c|c|c|c|c|}
\hline Municípios & $\begin{array}{l}\text { Deficiência } \\
\text { hídrica }(\mathrm{mm})\end{array}$ & $\begin{array}{l}\text { Classifi } \\
\text { cação }\end{array}$ & Municípios & $\begin{array}{c}\text { Deficiência } \\
\text { Hídrica }(\mathrm{mm})\end{array}$ & $\begin{array}{c}\text { Classifi } \\
\text { cação }\end{array}$ \\
\hline \multirow[t]{2}{*}{ Agricolândia } & & Restrita & & & Inapta \\
\hline & 652 & & Elizeu Martins & 752 & \\
\hline \multirow[t]{2}{*}{ Água Branca } & & Restrita & & & Inapta \\
\hline & 639 & & Esperantina & 709 & \\
\hline \multirow[t]{2}{*}{ Alagoinha } & & Inapta & & & Restrita \\
\hline & 938 & & Fartura do Piauí & 687 & \\
\hline \multirow[t]{2}{*}{ Alegrete do Piauí } & & Inapta & & & Inapta \\
\hline & 983 & & Flores do Piauí & 713 & \\
\hline \multirow[t]{2}{*}{ Alto Longa } & & Restrita & & & Inapta \\
\hline & 646 & & Floriano & 798 & \\
\hline \multirow[t]{2}{*}{ Altos } & & Inapta & & & Inapta \\
\hline & 794 & & Francinopolis & 710 & \\
\hline \multirow[t]{2}{*}{ Amarante } & & Inapta & & & Inapta \\
\hline & 720 & & Francisco Ayres & 787 & \\
\hline \multirow[t]{2}{*}{ Alvorada Gurguéia } & & Inapta & & & Inapta \\
\hline & 722 & & rancisco Macedo & 990 & \\
\hline \multirow[t]{2}{*}{ Angical do Piauí } & & Inapta & & & Inapta \\
\hline & 791 & & Francisco Santo & 908 & \\
\hline \multirow[t]{2}{*}{ Anísio de Abreu } & & Inapta & & & Inapta \\
\hline & 772 & & Fronteiras & 877 & \\
\hline \multirow[t]{2}{*}{ Antônio Almeida } & & Restrita & & & Inapta \\
\hline & 604 & & Geminiano & 1129 & \\
\hline \multirow[t]{2}{*}{ Aroazes } & & Inapta & & & Restrita \\
\hline & 779 & & Gilbués & 512 & \\
\hline \multirow[t]{2}{*}{ Arraial } & & Inapta & & & Restrita \\
\hline & 806 & & Guadalupe & 682 & \\
\hline \multirow[t]{2}{*}{ Avelino Lopes } & & Restrita & & & Inapta \\
\hline & 664 & & Hugo Napoleão & 702 & \\
\hline \multirow[t]{2}{*}{ Baixa G. Ribeira } & & Restrita & & & Restrita \\
\hline & 633 & & Inhuma & 689 & \\
\hline \multirow[t]{2}{*}{ Barras } & & Inapta & & & Restrita \\
\hline & 751 & & Ipiranga Piauí & 685 & \\
\hline \multirow[t]{2}{*}{ Barra Alcântara } & & Inapta & & & Inapta \\
\hline & 861 & & Isaias Coelho & 966 & \\
\hline \multirow[t]{2}{*}{ Barreira do Piauí } & & Restrita & & & Inapta \\
\hline & 543 & & Itainópolis & 1014 & \\
\hline \multirow[t]{2}{*}{ Barro Duro } & & Restrita & & & Restrita \\
\hline & 635 & & Itaueira & 693 & \\
\hline \multirow[t]{2}{*}{ Batalha } & & Restrita & & & Inapta \\
\hline & 684 & & Jacobina Piauí & 908 & \\
\hline \multirow[t]{2}{*}{ Bela Vista } & & Inapta & & & Inapta \\
\hline & 946 & & Jaicós & 965 & \\
\hline \multirow[t]{2}{*}{ Beneditinos } & & Inapta & & & Inapta \\
\hline & 711 & & Jatobá & 806 & \\
\hline Bertolínia & & Restrita & & & Inapta \\
\hline & 605 & & Jerumenha & 724 & \\
\hline Bocaina & & Inapta & & & Inapta \\
\hline & 988 & & João Costa & 952 & \\
\hline
\end{tabular}




\begin{tabular}{|c|c|c|c|c|c|}
\hline \multirow[t]{2}{*}{ Bom Jesus } & \multicolumn{3}{|c|}{ Restrita } & \multicolumn{2}{|r|}{ Inapta } \\
\hline & 638 & & Joaquim Pires & 777 & \\
\hline \multirow[t]{2}{*}{ Bom Principio Piauí } & & Inapta & & & Restrita \\
\hline & 861 & & Joca Marques & 679 & \\
\hline \multirow[t]{2}{*}{ Bomfim do Piauí } & & Inapta & & & Restrita \\
\hline & 931 & & José de Freitas & 695 & \\
\hline \multirow[t]{2}{*}{ Betânia } & & Inapta & & & Inapta \\
\hline & 954 & & Júlio Borges & 1055 & \\
\hline \multirow[t]{2}{*}{ Boa hora } & & Inapta & & & Inapta \\
\hline & 734 & & Jurema & 700 & \\
\hline \multirow[t]{2}{*}{ Brasileira } & & Inapta & & & Inapta \\
\hline & 738 & & Lagoa Alegre & 746 & \\
\hline \multirow[t]{2}{*}{ Buriti do Lopes } & & Inapta & & & Inapta \\
\hline & 761 & & Lagoa Barro & 968 & \\
\hline \multirow[t]{2}{*}{ Buriti dos Montes } & & Restrita & & & Restrita \\
\hline & 621 & & Lagoa Piauí & 668 & \\
\hline \multirow[t]{2}{*}{ Cabeceiras Piauí } & & Inapta & & & Inapta \\
\hline & 760 & & L.S. Francisco & 739 & \\
\hline \multirow[t]{2}{*}{ Caldeirão Grande } & & Inapta & & & Inapta \\
\hline & 1197 & & Lagoa Sítio & 702 & \\
\hline \multirow[t]{2}{*}{ Campinas Piauí } & & Inapta & & & Restrita \\
\hline & 889 & & Lagoinha & 661 & \\
\hline \multirow[t]{2}{*}{ Campo Alegre } & & Inapta & & & Restrita \\
\hline & 1049 & & Landri Sales & 510 & \\
\hline \multirow[t]{2}{*}{ Campo Grande } & & Inapta & & & Inapta \\
\hline & 838 & & Luís Correia & 895 & \\
\hline \multirow[t]{2}{*}{ Cajazeiras } & & Inapta & & & Inapta \\
\hline & 1165 & & Luzilândia & 707 & \\
\hline \multirow[t]{2}{*}{ Cajueiro } & & Inapta & & & Inapta \\
\hline & 898 & & Madeiro & 833 & \\
\hline \multirow[t]{2}{*}{ Campo Maior } & & Inapta & & & Inapta \\
\hline & 788 & & Manoel Emídio & 742 & \\
\hline Canavieira & & Inapta & & & Restrita \\
\hline & 914 & & Marcolândia & 525 & \\
\hline Canto do Buriti & & Inapta & & & Restrita \\
\hline & 785 & & Marcos Parente & 618 & \\
\hline Cap. Gerv. Oliveira & & Inapta & & & Inapta \\
\hline & 775 & & Massapê & 1119 & \\
\hline Capitão Campos & & Inapta & & & Restrita \\
\hline & 780 & & Matias Olímpio & 614 & \\
\hline Caracol & & Restrita & & & Restrita \\
\hline & 535 & & Miguel Alves & 663 & \\
\hline Campo Largo & & Restrita & & & Inapta \\
\hline & 572 & & Miguel Leão & 778 & \\
\hline Castelo do Piauí & & Inapta & & & Inapta \\
\hline & 793 & & Milton Brandão & 852 & \\
\hline Cocal & & Inapta & & & Inapta \\
\hline & 766 & & Monsenhor Gil & 703 & \\
\hline Cocal Alves & & Inapta & & & Inapta \\
\hline & 1074 & & Mons. Hipólito & 1054 & \\
\hline Cocal de Telha & & Inapta & & & Restrita \\
\hline & 860 & & Monte Alegre & 539 & \\
\hline Colônia Gurguéia & & Inapta & & & Inapta \\
\hline & 948 & & Morro Chapéu & 944 & \\
\hline Colônia Piauí & & Inapta & & & Inapta \\
\hline & 941 & & Murici Portelas & 776 & \\
\hline
\end{tabular}




\begin{tabular}{|c|c|c|c|c|c|}
\hline \multirow[t]{2}{*}{ Conceição Canidé } & & Inapta & & & Inapta \\
\hline & 946 & & N. S. Remédios & 758 & \\
\hline \multirow[t]{2}{*}{ Coronel José Dias } & & Inapta & & & Inapta \\
\hline & 999 & & Nova Santa Rita & 976 & \\
\hline \multirow[t]{2}{*}{ Caraúbas } & & Inapta & & & Inapta \\
\hline & 866 & & Novo Oriente & 834 & \\
\hline \multirow[t]{2}{*}{ Caridade } & & Inapta & & & Inapta \\
\hline & 988 & & Novo S. Antônio & 850 & \\
\hline \multirow[t]{2}{*}{ Corrente } & & Restrita & & & Inapta \\
\hline & 507 & & Oeiras & 828 & \\
\hline \multirow[t]{2}{*}{ Cristalândia } & & Restrita & & & Inapta \\
\hline & 507 & & Olho D'água & 732 & \\
\hline \multirow[t]{2}{*}{ Cristino Castro } & & Inapta & & & Inapta \\
\hline & 701 & & Padre Marcos & 981 & \\
\hline \multirow[t]{2}{*}{ Curimatá } & & Restrita & & & Inapta \\
\hline & 634 & & Paes Landim & 934 & \\
\hline \multirow[t]{2}{*}{ Caxingó } & & Inapta & & & Inapta \\
\hline & 883 & & Pajeú do Piauí & 779 & \\
\hline \multirow[t]{2}{*}{ Currais } & & Restrita & & & Inapta \\
\hline & 647 & & Palmeira Piauí & 745 & \\
\hline \multirow{2}{*}{ Curralinhos } & & Inapta & & & Inapta \\
\hline & 876 & & Palmeirais & 722 & \\
\hline \multirow[t]{2}{*}{ D. Expedito Lopes } & & Inapta & & & Inapta \\
\hline & 710 & & Paquetá & 874 & \\
\hline \multirow[t]{2}{*}{ Demerval Lobão } & & Inapta & & & Restrita \\
\hline & 768 & & Parnaguá & 542 & \\
\hline \multirow[t]{2}{*}{ Dirceu Arcoverde } & & Restrita & & & Inapta \\
\hline & 571 & & Parnaíba & 869 & \\
\hline \multirow[t]{2}{*}{ Dom Inocêncio } & & Inapta & & & Inapta \\
\hline & 1009 & & Pas. Franca & 764 & \\
\hline \multirow[t]{2}{*}{ Domingos Mourão } & & Inapta & & & Inapta \\
\hline & 917 & & Patos do Piauí & 1008 & \\
\hline \multirow[t]{2}{*}{ Elesbão Veloso } & & Inapta & & & Inapta \\
\hline & 798 & & Paulistana & 1004 & \\
\hline \multirow[t]{2}{*}{ Pavussu } & & Inapta & & 934 & Inapta \\
\hline & 771 & & Santa Cruz Piau & & \\
\hline Pedro II & & Restrita & & 781 & Inapta \\
\hline & 458 & & S. Cruz Milagre: & & \\
\hline Pedro laurentino & & Inapta & & 577 & Restrita \\
\hline & 990 & & Santa Filomena & & \\
\hline Picos & & Inapta & & 666 & Inapta \\
\hline & 998 & & Santa Luz & & \\
\hline Pimenteiras & & Inapta & & 913 & Inapta \\
\hline & 819 & & Santa Rosa & & \\
\hline Pio IX & & Inapta & & 874 & Inapta \\
\hline & 741 & & Santana do Piau & & \\
\hline Piracuruca & & Inapta & & 923 & Inapta \\
\hline & 806 & & S. Antônio Lisboa & & \\
\hline Piripiri & & Restrita & & 844 & Inapta \\
\hline & 683 & & S. Inácio Piauí & & \\
\hline Porto & & Inapta & & 777 & Inapta \\
\hline & 723 & & São Braz Piauí & & \\
\hline Porto Alegre & & Restrita & & 614 & Restrita \\
\hline & 647 & & São Félix Piauí & & \\
\hline Prata do Piauí & & Inapta & & 807 & Inapta \\
\hline & 788 & & S. Francisco Piaui & & \\
\hline
\end{tabular}




\begin{tabular}{|c|c|c|c|c|c|}
\hline \multirow[t]{2}{*}{ Queimada Nova } & & Inapta & & 619 & Restrita \\
\hline & 1041 & & S. Gonçalo Piauí & & \\
\hline \multirow[t]{2}{*}{ Redenção Gurguéia } & & Restrita & & 1008 & Inapta \\
\hline & 683 & & S.J. Canabrava & & \\
\hline \multirow[t]{2}{*}{ Regeneração } & & Inapta & & 869 & Inapta \\
\hline & 711 & & São J. Serra & & \\
\hline \multirow[t]{2}{*}{ Riacho Frio } & & Inapta & & 1058 & Inapta \\
\hline & 704 & & S. J. Varjota & & \\
\hline \multirow[t]{2}{*}{ Ribeira } & & Inapta & & 1024 & Inapta \\
\hline & 1086 & & São J. do Piauí & & \\
\hline \multirow[t]{2}{*}{ Ribeiro Gonçalves } & & Restrita & & 946 & Inapta \\
\hline & 630 & & São J. Divino & & \\
\hline \multirow[t]{2}{*}{ Rio Grande Piauí } & & Restrita & & 817 & Inapta \\
\hline & 699 & & São J. Peixe & & \\
\hline \multirow[t]{2}{*}{ S. Antônio Milagre } & & Restrita & & 717 & Inapta \\
\hline & 698 & & São J. Piauí & & \\
\hline \multirow[t]{2}{*}{ S. Francisco Assis } & & Inapta & & 893 & Inapta \\
\hline & 951 & & São Julião & & \\
\hline \multirow[t]{2}{*}{ S.Gonçalo Gurguéia } & & Restrita & & 732 & Inapta \\
\hline & 542 & & S. Lourenço & & \\
\hline \multirow[t]{2}{*}{ S. J. Arraial } & & Inapta & & 859 & Inapta \\
\hline & 767 & & São Luís Piauí & & \\
\hline \multirow[t]{2}{*}{ S. J. Fronteira } & & Inapta & & 828 & Inapta \\
\hline & 871 & & S. M. Tapuio & & \\
\hline \multirow[t]{2}{*}{ S. Miguel B.Grande } & & Inapta & & 599 & Restrita \\
\hline & 789 & & S. Pedro Piauí & & \\
\hline \multirow{3}{*}{$\begin{array}{l}\text { S. Miguel Fidalgo } \\
\text { Sebastião Barros }\end{array}$} & 902 & Inapta & S. R. Nonato & 860 & Inapta \\
\hline & & Restrita & & & Inapta \\
\hline & 492 & & Tanque & 809 & \\
\hline \multirow[t]{2}{*}{ Sebastião Leal } & & Restrita & & & Inapta \\
\hline & 508 & & Teresina & 766 & \\
\hline \multirow[t]{2}{*}{ Sigefredo Pacheco } & & Inapta & & & Restrita \\
\hline & 982 & & União & 698 & \\
\hline \multirow[t]{2}{*}{ Simões } & & Inapta & & & Restrita \\
\hline & 848 & & Uruçuí & 612 & \\
\hline \multirow[t]{2}{*}{ Simplício Mendes } & & Inapta & & & Inapta \\
\hline & 719 & & Valença Piauí & 716 & \\
\hline \multirow[t]{2}{*}{ Socorro do Piauí } & & Inapta & & & Inapta \\
\hline & 1020 & & Várzea Branca & 760 & \\
\hline \multirow[t]{2}{*}{ Sussuapara } & & Inapta & & & Inapta \\
\hline & 963 & & Várzea Grande & 719 & \\
\hline \multirow[t]{2}{*}{ Tamboril } & 788 & Inapta & & 1034 & Inapta \\
\hline & & & Vera Mendes & & \\
\hline Vila Nova & 1100 & Inapta & Wall Ferraz & 1391 & Inapta \\
\hline
\end{tabular}

Fonte: Dados da Pesquisa

Na Figura 1 tem-se o mapa de aptidão climática da cultura da banana no estado do Piauí, onde se estabelece duas classes de aptidões bem definidas: restritas e inaptada. $\mathrm{Na}$ aptidão restrita pode-se realizar-se o plantio e utilizar-se de tratamento de solo e água para irrigação.

Figura 1. Aptidão climática da cultura da banana para o estado do Piauí. 
Fonte: Autor

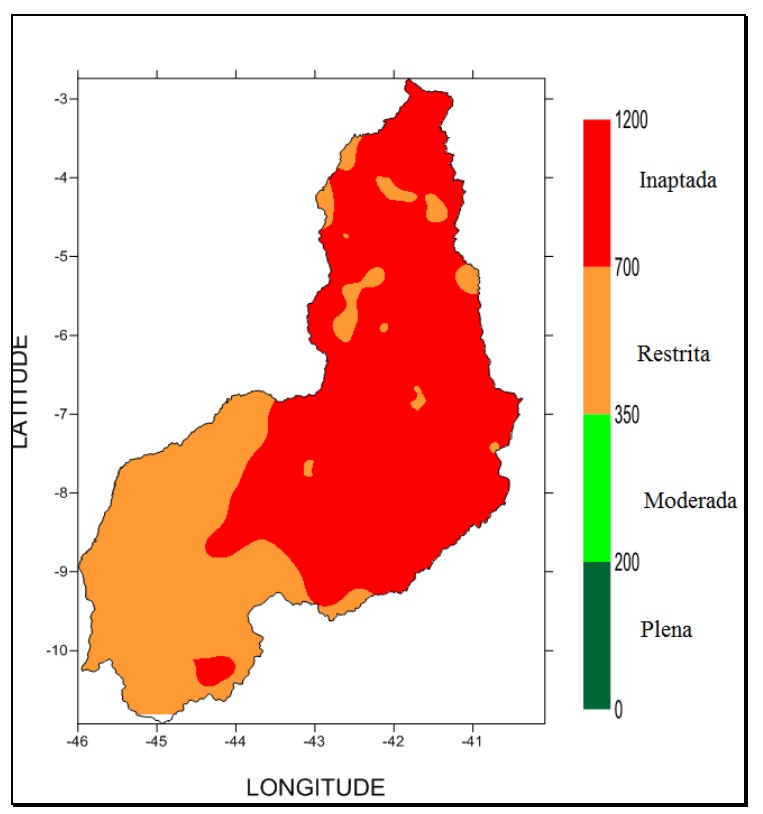

As variáveis utilizadas na determinação do balanço hídrico climatológico para o período de 30 a 100 no estado do Piauí encontram-se na Tabela 4 conforme a Figura 1, considerando a capacidade de armazenamento de água disponível (CAD) $100 \mathrm{~mm}$. O consumo de quanto realmente está sendo evapotranspirado de água é expresso pela evapotranspiração real (ETR), que se comportou de forma semelhante à distribuição da precipitação pluvial.

Através do balanço hídrico climatológico foi possível determinar os índices de aridez (la), umidade (Iu), hídrico (Ih) e o CV, onde o CV é a concentração da evapotranspiração potencial na estação quente, determinada pelos três meses consecutivos de temperatura mais elevada do ano (trimestre mais quente). Tais índices determinam a classificação climática, baseada em observações e estudos realizados nas condições do Sudeste árido dos Estados Unidos da América e aplicado ao resto do mundo, proposto por Thornthwaite (1948).

A Tabela 4 representa o balanço hídrico climatológico médio do estado do Piauí, observase que a temperatura média oscila entre $25,3^{\circ} \mathrm{C}$

Tabela 4. Balanço hídrico climatológico do estado do Piauí. no mês de fevereiro a $28,3{ }^{\circ} \mathrm{C}$ nos meses de outubro com uma temperatura média anual de $26,5^{\circ} \mathrm{C}$.

A precipitação média anual dos 221 municípios piauiense é de $943,7 \mathrm{~mm}$, o trimestre chuvoso esta representado pelos meses de janeiro, fevereiro e março com flutuação entre 166,4 a $210,5 \mathrm{~mm}$ mês $^{-1}$, os trimestres secos ocorrem nos meses de julho, agosto e setembro e fluem entre 2 a 5,6 $\mathrm{mm}$ mês $^{-1}$.

A evapotranspiração potencial anual é de $1.630,1 \mathrm{~mm}$, o trimestre com maiores valores evaporativo ocorre nos meses de agosto, setembro e outubro, sua oscilação mensal flui entre 142,2 a $178,5 \mathrm{~mm}$, nos meses de fevereiro, março e abril ocorrem os menores índices evaporativos fluindo entre 106,6 a 124,1 mm.

A evaporação real anual é de $2.319,5 \mathrm{~mm}$, os meses de maiores evaporações ocorrem entre setembro, outubro e novembro oscilando entre 234,4 a $253,7 \mathrm{~mm}$ e os meses de fevereiro, março e abril ocorrem os menores índices evaporativos com flutuações entre 151,7 a 176,4 mm.

\begin{tabular}{ccccccc}
\hline Meses & $\mathrm{T}$ & $\mathrm{P}$ & $\mathrm{ETP}$ & EVR & DEF & EXC \\
\cline { 2 - 6 } & $\left({ }^{\circ} \mathrm{C}\right)$ & $(\mathrm{mm})$ & $(\mathrm{mm})$ & $(\mathrm{mm})$ & $(\mathrm{mm})$ & $(\mathrm{mm})$ \\
\hline Jan & 25,9 & 166,4 & 126,3 & 126,3 & 0,0 & 0,0 \\
Fev & 25,3 & 171,3 & 108,3 & 108,3 & 0,0 & 3,1 \\
Mar & 25,7 & 210,5 & 124,9 & 124,9 & 0,0 & 85,6 \\
Abr & 25,6 & 150,7 & 117,8 & 117,8 & 0,0 & 32,9 \\
Mai & 25,7 & 54,7 & 120,7 & 103,0 & 17,7 & 0,0 \\
Jun & 27,2 & 12,0 & 143,4 & 49,8 & 93,6 & 0,0
\end{tabular}




\begin{tabular}{ccccccc} 
Jul & 25,7 & 5,3 & 119,9 & 14,7 & 105,1 & 0,0 \\
Ago & 26,7 & 2,0 & 139,1 & 5,3 & 133,8 & 0,0 \\
Set & 28,0 & 5,6 & 162,4 & 6,4 & 156,0 & 0,0 \\
Out & 28,3 & 21,6 & 177,1 & 21,8 & 155,3 & 0,0 \\
Nov & 27,7 & 55,0 & 160,3 & 55,0 & 105,3 & 0,0 \\
Dez & 26,7 & 88,6 & 145,9 & 88,6 & 57,3 & 0,0 \\
\hline
\end{tabular}

LEGENDA: Temperatura do ar média (T), Precipitação (P), Evapotranspiração potencial (ETP), Evaporação real (EVR), Deficiência hídrica (DEF) e Excesso Hídrico (EXC). Fonte: Autor

Figura 2. Representação Gráfica do balanço hídrico climatológico do estado do Piauí.

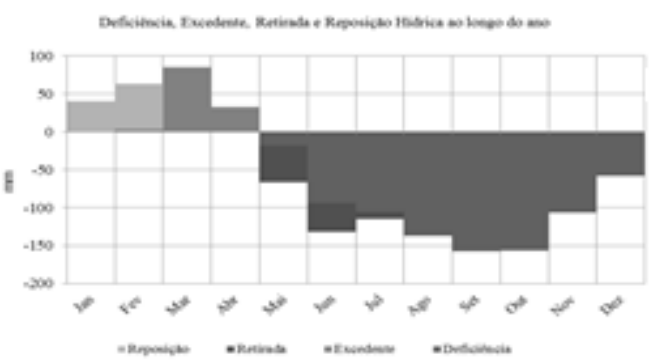

Fonte: Autor

Estas flutuações ocorrem devido às oscilações entre os períodos seco e chuvoso municipal, salienta-se ainda que as oscilações dos fatores provocadores e/ou inibidores de chuvas depende exclusivamente dos elementos de larga, meso e grande escala, assim como das contribuições dos efeitos locais, da orografia, do posicionamento da Zona de convergência Intertropical (ZCIT); a atuação dos Vórtices Ciclônico de Altos Níveis (VCAN); Zona de convergência do Atlântico Sul (ZCAS); Penetração de Frente fria quando em atividades; Troca de calor; Linha de Instabilidade.

O sistema de classificação climática de Thornthwaite (1948) permite separar eficientemente os climas de uma região, uma vez que o método é muito sensível aos totais de chuva, temperatura e relevo da região estudada, resultando em maior número de tipos climáticos, gerando informações eficientes através do balanço hídrico normal, demonstrando a capacidade para delimitação das zonas agroclimáticas de acordo com ROLIM et al. (2007).

Wollmann e Galvani (2013) relatam que as condições locais hídricas e de clima, são levadas em consideração no zoneamento agroclimático, visando à exploração de culturas economicamente rentáveis. São estas as características agroclimáticas desta localidade que determinam aptidão ao desenvolvimento das culturas.

$\mathrm{Na}$ Figura 3 tem-se a distribuição dos setores hídricos e faixas térmicas do evapopluviograma para o Estado do Piauí. Destacando que existem cinco tipos de clima predominante na área de estudo que são: árido, seco, subúmido, úmido e hipertérmica. 
Figura 3. Distribuição dos setores hídricos e faixas térmicas do evapopluviograma para o Estado do Piauí.

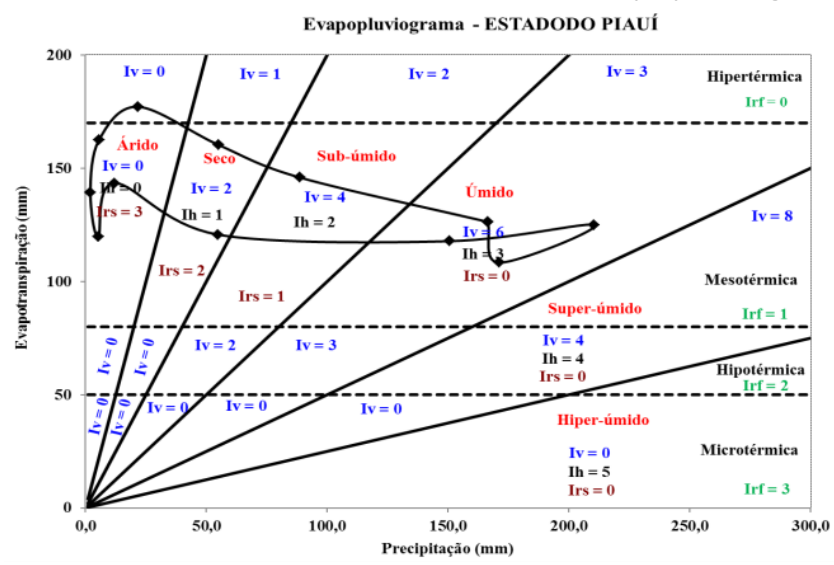

Fonte: Autor

\section{CONCLUSÕES}

Os municípios da região semiárida piauiense foram classificados como inaptos para produção de bananeira, pois ocorre altas déficit hídrico e falta água para complementação por irrigação o que pode ser evitando assim a queda da produtividade e o aparecimento de doenças devido ao estresse hídrico;

A bananeira que deve ser cultivada em locais que variam de 0 a 1.000 metros acima do nível do mar demostram altimetria dentro das citações de diversos autores. As oscilações na altitude alteram a duração do ciclo da bananeira, evidenciando-se que há um aumento de 30 a 45 dias no ciclo de produção desta cultura para cada $100 \mathrm{~m}$ de acréscimo na altitude;

$O$ vento pode ser um dos fatores limitantes para a exploração comercial da bananicultura, se as cultivares forem de portes altos e plantados em solos arenosos;

Para o estado do Piauí o modelo aplicado das deficiências hídricas não é representativo para a aptidão da cultura da bananeira.

\section{REFERÊNCIAS}

ANDRADE, A.; BASTOS,; BARROS, A.; SILVA, C; GOMES, A. Classificação climática e regionalização do semiárido do Estado do Piauí sob cenários pluviométricos distintos. Revista Ciência Agronômica, 36, 143-151. 2005.

BORGES, A. L.; SOUZA, L. S. O cultivo da bananeira. Embrapa mandioca e Fruticultura. 2004, 279p.

CAVALCANTI, E. P., SILVA, E. D. V. Estimativa da temperatura do ar em função das coordenadas locais. In: CONGRESSO BRASILEIRO DE METEOROLOGIA, 8., 1994. Belo Horizonte.
Anais... Belo Horizonte: SBMET, 1994. v.1, p.154157.

CAVALCANTI, E. P.; SILVA, V. P. R.; SOUSA, F. A. S. Programa computacional para a estimativa da temperatura do ar para a região Nordeste do Brasil. Revista Brasileira de Engenharia Agrícola e Ambiental, v.10, n.1, p.140-147, 2006. https://doi.org/10.1590/S1415$\underline{43662006000100021}$

EMATER-PI. Empresa de Assistência Técnica e Extensão Rural do Estado do Piauí. 2014.

KÖPPEN, W.; GEIGER, R. Klimate der Erde. Gotha: Verlag Justus Perthes. Wall-map. 1928.

FAO. STATISTICAL databases. Disponível em: <http:// www.fao.org>. Acesso em: 02 fev. 2016.

FERREIRA, E. J. Determinação da evapotranspiração e do coeficiente de cultura (Kc) para a aveia preta (Avena strigosa, Sckereb) irrigada. 1988. 70 f. Dissertação (Mestrado em Agronomia) - Universidade Federal de Viçosa, Viçosa - MG, 1988.

MARENGO, A. A.; SOARES, W. R.; SAULO, C.; NICOLINI, M. Climatology of the low-level jet east of the andes as derived from NCEP-NCAR reanalyses: characteristics and temporal variability. Journal of Climate, v. 17, n. 12 , p. 2261-2280, 2004. https://doi.org/10.1175/15200442(2004)017<2261:COTLE>2.0.CO;2

MATOS, R. M.; SILVA, J. A. S.; MEDEIROS, R. M. Aptidão climática para a cultura do feijão caupi do município de Barbalha - CE. Revista Brasileira 
de Agricultura Irrigada, v. 8, n. 6, p. 422-431, 2014. https://doi.org/10.7127/rbai.v8n600240

MEDEIROS, R. M. Programa em planilhas eletrônicas para preenchimentos de falhas pelo método da média ponderada pelo o inverso da distância ao quadrado. 2016.

MEDEIROS et al. Balanço hídrico climatológico e classificação climática de cultivo de banana em Lagoa Seca - PB. Revista Verde de Agroecologia e Desenvolvimento Sustentáve, v.10, n.3, p.148163, 2014.

MEDEIROS, R. M. Planilhas do Balanço Hídrico Normal segundo Thornthwaite e Mather (1955). s.n. 2014.

MEDEIROS et al. Balanço hídrico climatológico e classificação climática para a área produtora da banana do município de Barbalha, CE. Revista Brasileira de Agricultura Irrigada, v.7, n.4, p.258268, 2013, https://doi.org/10.7127/rbai.v7n400018.

MOREIRA, R. S. Banana: teoria e prática de cultivo. Campinas: Fundação Cargill, 1997. 335p.

OMETTO, J. C. Bioclimatologia vegetal. São Paulo: Ceres, 1981.

SANTOS, G. O.; HERNANDEZ, F. B. T.; ROSSETTI, J. C. Balanço hídrico como ferramenta ao planejamento agropecuário para a região de Marinópolis, noroeste do estado de São Paulo. Revista Brasileira de Agricultura Irrigada, v. 4, n. 3, p.142-149, 2010. https://doi.org/10.7127/rbai.v4n300010

SILVA et al. Desertificação e variabilidade pluviométrica em São João do Cariri -PB no período de 1911-2010 In: WORKSHOP INTERNACIONAL SOBRE ÁGUA NO SEMIÁRIDO BRASILEIRO, 1., 2013. Anais... Campina Grande, PB: Realize, 2013.

SUDENE. Dados pluviométricos mensais do Nordeste. Recife, 1990. 239p. (Série pluviometria; 5).

THORNTHWAITE, C. W. An approach towards a rational classification of climate. Geographical Review, London, v. 38, p. 55 - 94, 1948.
THORNTHWAITE, C. W.; MATHER, J. R. The water balance. Centerton, N.J.: Laboratory of Climatology, 1955. (Publication in Climatology; n.8)

VAREJÃO-SILVA, M. A. Meteorologia e Climatologia. Recife, 2005. 516p.

VENTURA, J. A.; GOMES, J. A. Recomendações técnicas para o cultivo de bananeira no Estado do Espírito Santo. Vitoria: Incaper, 2005. 42p.

VOSSELEN, V. A.; VERPLANCKE, H.; RANST, V. E. Assessing water consumption of banana: Traditional versus modeling approach. Agricultural Water Management, v.74, p.201218, 2005. https://doi.org/10.1016/j.agwat.2004.11.005

WOLLMANN, C. A.; GALVANI, E. Zoneamento agroclimático: linhas de pesquisa e caracterização teórica-conceitual. Sociedade e Natureza, v. 25, p. 179-190, 2013. https://doi.org/10.1590/S1982$\underline{45132013000100014}$

Recebido para publicação em 27/03/2018

Revisado em 16/08/2018

Aceito em 12/11/2018 